\title{
PREVALENCE OF DEPRESSION; HEPATITIS C DURING TREATMENT WITH COMBINATION OF PEGYLATED INTERFERON AND RIBAVIRIN IN OUR POPULATION.
}

1. Associate. Professor of Medicine Fatima Memorial Medical College, Lahore

2. Assist. Professor Gastroenterology Fatima Memorial Medical College, Lahore

3. Associate. Professor of Medicine Fatima Memorial Medical College Lahore

Correspondence Address: Dr. Mirza Muhammad llyas Baig Fatima Memorial Medical College Shadman, Lahore.

dr.muhd.ib@gmail.com

Article received on: 29/01/2016

Accepted for publication: 15/04/2016

Received after proof reading: $26 / 05 / 2016$

\section{Dr. Mirza Muhammad llyas Baig ${ }^{1}$, Dr. Aftab Haider Alvi², Dr. Nazeefa Javed ${ }^{3}$}

ABSTRACT... With recent availability of Sofosbuvir, Chronic Hepatitis C treatment paradigm has changed considerably. However for a resource constrained country like Pakistan, still the standard treatment of Chronic Hepatitis $\mathrm{C}$ remains the combination of Interferons and Ribavirin. Depression, sometimes major, is a recognized side effect of this combination. Objective: The objective of our study was to analyze the prevalence of depression during treatment with pegylated interferon and ribavirin in patients infected with Hepatitis $\mathrm{C}$ at two tertiary care hospitals Lahore. Setting: All these patients were selected randomly from outpatient departments at Fatima Memorial Hospital and Alshafi Hospital Lahore. Duration of study: Duration of our study was two years and 3 months from January 2010 to April 2012. Patients and Method: We included 180 patients in our study. We confirmed the diagnosis of chronic hepatitis $C$ in all these willingly participated patients. All these participants were put on combination of pegylated interferon and ribavirin. Serial follow ups were done for the assessment of development of depression during the treatment of Hepatitis C. Results: 46.8 (26\%) patients developed depression during treatment. Depression was more common in the middle of treatment which gradually improved near the end of treatment. Conclusion: We reached at a conclusion in our study that there is definite correlation of depression with pegylated interferon and ribavirin therapy in hepatitis $\mathrm{C}$ patients.

Key words: $\quad$ Chronic Active Hepatitis C, Pegylated Interferon, Ribavirin, Depression.

\section{INTRODUCTION}

Hepatitis $C$ infection is worldwide health problem with estimated $130-170$ million people infected and approximately 4 million new cases each year. ${ }^{1}$ Hepatitis $C$, which is now the leading cause of cirrhosis of liver and eventually liver transplantation all over the world. ${ }^{2,3}$ This infection of hepatitis $\mathrm{C}$ leads to a number of deaths exceeding to more than 350,000 per year. ${ }^{4}$ Pakistan is one the countries where the prevalence of hepatitis $\mathrm{C}$ is still at peak. The pharmacological advances in HCV treatment is gradually progressing for better and easy treatment. As sofosbuvir is the latest advancement for the treatment of hepatitis $\mathrm{C}$ now a days. Our study was conducted three years ago when the best available treatment was combination of pegylated interferon and ribavirin at that time. As we know that pegylated interferon has extended half-life and increased rate of sustained virological response with once weekly dosage as compared to conventional interferon, given three times per week along with ribavirin. Pegylated interferon plus ribavirin was considered the back bone to antiviral therapy for patients infected with chronic hepatitis $C$. As we know that combination of this therapy is poorly tolerated by patients due its side effects profile, which include many side effects but depression is one of the side effects which is considered more embarrassing for patients. ${ }^{5}$ Recent data suggest that decreased occurrence of depression with pegylated interferon as compared to conventional interferons. $^{6}$

It has been proven as the best efficacy of pegylated interferon and ribavirin in chronic active hepatitis $C$ treatment even then this combination may lead to the development of depression in certain 
patients during therapy. ${ }^{7}$ Mental health issues may also reduce quality of life and interfere with treatment compliance ${ }^{8}$ and are among the most frequent reason for premature discontinuation of therapy. ${ }^{9,10,11}$ It has been proven that even with the development of these depressive episodes, it would not had any effect on End of Treatment Response (ETR). ${ }^{12,13}$

Depression as a complication of this regimen, with peak of symptoms commonly during midtreatment period. ${ }^{14}$ Upto $50 \%$ of all treatment of hepatitis $C$ results leading to failure and the most important factor of this treatment is depression. ${ }^{15}$

It has been shown that many patients develop depression as a side effect of this combination during the course of treatment, most of these affected patients did not have any history of depressive episode in the past. ${ }^{16}$ Those patients who already had some depression, they showed the increased chance of worsening of already existing depression. ${ }^{17}$ Even with the start of antidepressants to reduce this complication still about $10 \%$ of patients stop their treatment prematurely. ${ }^{18}$ We tried to evaluate the element of depression subjective to signs and symptoms in patients infected with hepatitis $\mathrm{C}$ and also during the treatment with pegylated interferon and ribavirin.

\section{Aims of study}

To assess the prevalence of depression during pegylated interferon and ribavirin treatment in patients with chronic active hepatitis $C$ in our population.

\section{MATERIAL AND METHOD}

We enrolled 180 patients from Out Patient Departments of Fatima Memorial Hospital and Alshafi Hospital from January 2010 to April 2012. All these patients were HCV positive confirmed by ELISA and by PCR HCV RNA was detected. All subjects had chronic active hepatitis $C$ with compensated liver disease. These participants volunteered for participation for their clinical assessment and follow up. A written consent was taken from all patients and consent from ethical research committee of Fatima Memorial Hospital was also taken. These patients were treated as outdoor patients. These patients were assessed for their treatment eligibility. Symptoms of depression were assessed by using DSM-IV latest guidelines having 9 points scale. Following this scale $<6$ is considered mild, $6-8$ moderate and $>8$ points is considered as having severe depression. We assessed each patient for his/her any symptom of depression before the start of treatment. This assessment was done according to the new guidelines of DSM-IV. ${ }^{19}$

\begin{tabular}{|c|c|}
\hline $\begin{array}{l}\text { Total Number of Patients } \\
\qquad(\mathbf{N}) \text { : }\end{array}$ & 180 \\
\hline Gender Distribution & $\begin{array}{l}\text { Males: } 110(61.1 \%) \text {. } \\
\text { Females: } 70(38.8 \%)\end{array}$ \\
\hline Mean Age (years) & $?(24-65)$ \\
\hline Follow Up & Frequency of Depression \\
\hline 4 weeks & $\begin{array}{c}16(8.9 \%) \\
\text { ơ: } 10 \\
\text { ㅇ: } 6\end{array}$ \\
\hline 8 weeks & $\begin{array}{c}28(15.5 \%) \\
\text { o': } 12 \\
\text { : } 16\end{array}$ \\
\hline 12 weeks & $\begin{array}{c}47(26.1 \%) \\
\text { o: } 21 \\
\text { : } 26\end{array}$ \\
\hline 24 weeks & $\begin{array}{c}40 \\
o: 16 \\
\text { o: } 24\end{array}$ \\
\hline
\end{tabular}

We downloaded standard performa which was elaborated in English and urdu for the convenience of our patients, so that they can understand the questionnaire and can answer them accurately. After proper surveillance of this performa and detailed history of all these participants, we started the combination of therapy with pegylated interferon and ribavirin. We discussed the possible side effects of this regimen to all our patients. A dose of 180 microgram of pegylated interferon and $800-1200 \mathrm{mg}$ adjusted according to the weight of patients. These patients were assessed repeatedly with follow up at $4,8,12$, and 24 weeks and even 12 weeks after completion of therapy. 


\section{Inclusion Criteria}

All patients of both genders more than 18 years of age who were anti-HCV positive by ELISA, and HCV-RNA PCR positive were included in this study.

\section{Exclusion Criteria}

Patient who were already known cases of some psychiatric illness, alcoholics, intravenous drug abusers, previous history of interferon therapy, pregnancy, decompensated liver disease and non-responders of interferon treatment.

\section{RESULTS}

A total of 180 patients volunteered to participate in our study and completed their psychiatric assessment during pegylated interferon and ribavirin treatment. Out of 180 patients 110 were males and 70 were females. Basic demographic data is presented in Table I. All patients in our study received pegylated interferon alpha $2 a$ $180 \mathrm{mcg}$ and ribavarin 800 to1200 mg depending on the weight of patient. These patients were frequently assessed for mental health changes on $4,8,12$, and 24 weeks during treatment and also that follow up continued 12 weeks after treatment completion.

Among all enrolled patients, 7 (3.88\%) patients withdrew treatment due to severe depression and these patients were referred to psychiatrist, these patients were started on SSRIs. And these patients were counseled for continuation of therapy after improvement of depressive symptoms.

\section{2 weeks after completion of therapy}

Patients who had developed depressive symptoms during the course of treatment only $50 \%$ had follow up for assessment of their depressive symptoms 12 weeks after completion of treatment. It was found that $60 \%$ of patients who had depression had marked improvement and most of them left anti- psychiatric medication by their own. Patients in which there was major depression continued their medication for further 6 months and remained with follow up with psychiatric department and other patients in which mild to moderate depression left medication earlier.

By having these results, it was found that $26 \%$ patients developed depressive symptoms fulfilling the criteria of DSV-IV. In our study it was also found that female patients developed more depression as compared to male patients.

\section{DISCUSSION}

Psychiatric disorders are frequently associated with treatment of chronic hepatitis $\mathrm{C}$ with combination of pegylated interferon and ribavirin. Most of treated patients continue treatment, some of them need antidepressants, and few of them are unable to tolerate these side effects and leave treatment without completing the required duration of therapy. So it is better to understand the depression during pegylated interferon and ribavirin therapy to identify patients early in the treatment who may be at risk of adverse and sometimes treatment limiting side effects. During $\mathrm{HCV}$ treatment with IFN-based regimens the prevalence of depression has been reported to be between $10 \%-40 \%$ depending on the screening method used. ${ }^{20}$

No significant association of depression was found in the first week of treatment but as the time of treatment progressed the development of depressive symptoms increased. In one study which compared the depressive disorder in treated and untreated groups of patients, it was found that $37.9 \%$ of hepatitis $C$ treated group developed major depression. ${ }^{21}$ In another study done as systematic review and meta-analysis in which it was shown that 1 in 4 chronic hepatitis $C$ patients who started interferon plus ribavirin treatment developed major depression. ${ }^{22}$ Depressive symptoms occur mostly in the early stages of treatment and reach at peak between 4 to 16 weeks. ${ }^{23}$ In concordance with other relevant researches, majority showed the peak depressive symptoms during the mid of treatment period as we also found that worsening of symptoms near the middle of treatment in our study. The results of Date study proved a significant increase in depression due to the combination of pegylated interferon and ribavirin therapy and these 
symptoms started as early as 4 weeks after the initiation of therapy which also favored our study results.

In our country with various studies that proved strong association of major depressive disorder with this combination of treatment. In one study done locally in our country, prevalence of depression was more frequent in females than males having results of $44.4 \%$ in females and $28.7 \%$ in males. ${ }^{24,25}$ Which is quite similar to our study as we also concluded that our females are more prone to depression with this combined therapy.

The conclusion in the following study that $39 \%$ patients developed depression of moderate to severe intensity (i-e; SDS index score $>6$ ) during the treatment with combination of pegylated interferon and ribavirin. ${ }^{26} 29 \%$ of patients who were put on lower dosage regimen once weekly, also reported depression by themselves, proven by study, which is quite similar to our study. ${ }^{27}$

New onset depression was also noted in $35 \%$ of patients 12 weeks after the start of treatment, the results of this study were slightly higher than our study. In this respective study 7 patients stopped treatment prematurely due to psychiatric reasons which was quite in concordance to the study done by Alavi et al in which 6\% participant discontinued therapy prematurely due to side effects. ${ }^{28,29}$

In clinical trials excluding intravenous drug users, approximately $10 \%$ of patients discontinued required treatment due to depressive side effects, compared to our study we found lesser number of patients who stopped treatment prematurely. ${ }^{30,31}$

It has been proven that depression has no effect on treatment outcome i-e End of Treatment Response (ETR) but definitely impair the psychological wellbeing of patients. Psychological health and willing for treatment is an important factor for the continuation of therapy for required duration.

\section{CONCLUSION}

We concluded in our study that some patients do develop depression during hepatitis $\mathrm{C}$ treatment with pegylated interferon and ribavirin.

It is necessary to rule out the already existing psychiatric disorder before the start of treatment of hepatitis $\mathrm{C}$ to prevent further worsening of depression and discontinuation of treatment.

\section{Inference}

It has been observed that those patients who had proper and repeated counseling about the expected side effects of hepatitis $C$ treatment, they were more in a position to tolerate these side effects and continue the standard treatment for the required period of duration.

Copyright(C) 15 Apr, 2016.

\section{REFERENCES}

1. The global burden of hepatitis C. Lavanchy D Liver Int. 2009 Jan; 29 Suppl 1():74-81.

2. World Health Organization. Prevention and control of viral hepatitis infection: framework for global action. Geneva: World Health Organization; 2012.

3. Institute of Medicine. Hepatitis and liver cancer: a national strategy for prevention and control of hepatitis B and C. Washington DC: The National Academies Press; 2010.

4. World Health Organization. Hepatitis C Fact Sheet. 2011. Available from: http://www.who.int/mediacentre/ factsheets/fs164/en/. Accessed February 8, 2012.

5. Donna M. Evon, Denise E. Esserman, Meredith A. Howell, and Rachel A. Ruffin Pegylated Interferon Pharmacokinetics and Self-Reported Depressive Symptoms During Antiviral Treatment for Chronic Hepatitis C. pharmacopsychiatry.2014 sept; 47(6): 195201.

6. Manns MP, McHutchison JG, Gordon SC, et al. Peginterferon alfa-2b plus ribavirin compared with interferon alfa-2b plus ribavirin for initial treatment of chronic hepatitis C: a randomized trial. Lancet. 2001;358(9286):958-965.

7. Socka linfam s, Balderson K. Major depressive episode with psychotic features induced by pegylated interferon Alpha-2b and ribavirin treatment. int clin psycho pharmcol. 2005 Sep; 20(5): 289-90.

8. Laura A. Lucaciu and Dan L. Dumitrascu. Depression and suicide ideation in chronic hepatitis $C$ patients untreated and treated with interferon: prevalence, 
prevention, and treatment Ann Gastroenterol. 2015 Oct-Dec; 28(4): 440-447.

9.Effects of recognizing depression with a standardized questionnaire (CES-D) versus patient reporting of depression after a single-standardized question on the outcomes of treatment for hepatitis C with pegylated interferon- $\alpha-2 b$ and ribavirin 2010 Dec;22(12):1435-42.

10. Martín-Santos R, Díez-Quevedo $C$, Castellví $P$, Navinés R, Miquel M, Masnou H, Soler A, Ardevol M, García F, Galeras JA, Planas R, Solà R. De novo depression and anxiety disorders and influence on adherence during peginterferon-alpha-2a and ribavirin treatment in patients with hepatitis C. Aliment Pharmacol Ther. 2008 Feb 1;27(3):257-65

11. Maddrey WC Safety of combination interferon alfa$2 \mathrm{~b}$ /ribavirin therapy in chronic hepatitis C-relapsed and treatment-naive patients. Semin Liver Dis. 1999; 19 Suppl 1():67-75.

12. Dieperink E, Willenbring M, Ho SB. Neuropsychiatric symptoms associated with hepatitis $\mathbf{C}$ and interferon alpha: a review. Am J Psychiatry. 2000;157:867-876.

13. Schaefer M, Schmidt F, Folwaczny C, et al. Adherence and mental side effects during hepatitis $C$ treatment with interferon alfa and ribavirin in psychiatric risk groups. Hepatology. 2003;37:443-451. J Gastroenterol Hepatol. 2012 May;27(5):957-65.

14. Evon DM, Ramcharran D, Belle SH, Terrault NA, Fontana RJ, Fried MW, - Prospective analysis of depression during peginterferon and ribavirin therapy of chronic hepatitis C: results of the Virahep-C Study Group. Am J Gastroenterol. 2009 Dec; 104(12):2949-58.

15. Ogawa E, Furusyo N, Kajiwara E, Takahashi K, et al. Evaluation of the adverse effect of premature discontinuation of pegylated interferon $a-2 b$ and ribavirin treatment for chronic hepatitis C virus infection: results from Kyushu University Liver Disease Study; .J Gastroenterol Hepatol. 2012 Jul;27(7):1233-40.

16. Joerg F. Schlaak, Martin Trippler, Carolina HoyoBecerra, Yesim Erim, Bernhard Kis, Bo Wang, Norbert Scherbaum, and Guido Gerken. Selective Hyperresponsiveness of the Interferon System in Major Depressive Disorders and Depression Induced by Interferon Therapy. Published online Jun 6, 2012.

17. Poynard T, Bedossa P, Opolon P. Natural history of liver fibrosis progression in patients with chronic hepatitis C: The OBSVIRC, METAVIR, CLINIVIR, and DOSVIRC groups. Lancet. 1997;349:825-832.
18. Jeffers LJ, Cassidy W, Howell CD, et al. Peginterferon alfa-2a (40 kd) and ribavirin for black American patients with chronic HCV genotype 1. Hepatology. 2004;39:1702-1708.

19. American Psychiatric Association. Diagnostic and Statistical Manual of Mental Disorders, Fourth Edition, Text Revision (DSM-IV-TR), American Psychiatric Association, Washington, DC 2000.

20. Zacks S, Beavers K, Theodore D, et al. Social stigmatization and hepatitis $C$ virus infection. J Clin Gastroenterol. 2006;40(3):220-224.

21. Mm B, A Y, U Y, Gm Sel-D, M A, H AG, E F, Mm el-S. Major depressive disorder and generalized anxiety disorder and response to treatment in hepatitis C patients in EgyptInt J Psychiatry Med. 2015;50(2):14762.

22. Udina $M$, Castellví $P$, Moreno-España J, Navinés $R$, Valdés $M$, Forns $X$, Langohr $K$, Solà $R$, Vieta $E$, Martín-Santos R. Interferon-induced depression in chronic hepatitis C: a systematic review and meta-analysis. J Clin Psychiatry. 2012 Aug;73(8):1128-38.

23. Dieperink E, Ho SB, Tetrick L, Thuras P, Dua K, Willenbring $M L$. Suicidal ideation during interferon-alpha2b and ribavirin treatment of patients with chronic hepatitis C. Gen Hosp Psychiatry. 2004 May-Jun; 26(3):23740.

24. Shakoor A, Shafqat F, Mehmud Te, Akram M, Riaz $S$, Iqbal $Z$, Khan AA. Frequency of depression and somatic symptoms in patients on interferon alpha/ ribavirin for chronic hepatitis C. J Ayub Med Coll Abbottabad. 2010 Oct-Dec;22(4):6-9.

25. Leutscher PD, Lagging M, Buhl MR. Evaluation of depression as a risk factor for treatment failure in chronic hepatitis C. Hepatology. 2010;52(2):430-435.

26. Phillips $F H$, Prebis $M$, Grumbeck $C$, Hale T, Cubillas $R$, Brown GR. Effects of recognizing depression with a standardized questionnaire (CES-D) versus patient reporting ofdepression after a single-standardized question on the outcomes of treatment for hepatitis $C$ with pegylated interferon- $\alpha-2 b$ and ribavirin. Eur $\mathrm{J}$ Gastroenterol Hepatol. 2010 Dec;22(12):1435-42.

27. McHutchison JG, Manns M, Patel K, Poynard T, Lindsay KL, Trepo C, Dienstag J, Lee WM, Mak C, Garaud JJ, Albrecht JK; International Hepatitis InterventionalTherapy GroupAdherence to combination therapy enhances sustained response in genotype-1-infected patients with chronichepatitis. C Gastro-enterology. 2002 Oct;123(4):1061-9.

28. Alavi M, Grebely J, Matthews GV, Petoumenos K, Yeung 
B, Day C, Lloyd AR, Van Beek I, Kaldor JM, Hellard M, Dore GJ, Haber PS; ATAHC Study Group Effect of pegylated interferon- $\alpha-2 a$ treatment on mental health during recent hepatitis $\mathbf{C}$ virus infection. $\mathbf{J}$ Gastroenterol Hepatol. 2012 May;27(5):957-65.

29. Schlaak JF, Trippler M, Hoyo-Becerra C, Erim Y, Kis B, Wang B, Scherbaum N, Gerken G. PLoS One. Selective hyper-responsiveness of the interferon system in major depressive disorders and depression induced by interferon therapy. 2012;7(6): Epub 2012 Jun

30. Fried MW, Shiffman ML, Reddy KR, Smith C, Marinos G, Goncales FL, Jr., et al. Peginterferon alfa-2a plus ribavirin for chronic hepatitis $\mathbf{C}$ virus infection. $\mathrm{N}$ Engl $\mathbf{J}$ Med. 2002;347:975-982.

31. Schmidt F, Janssen G, Martin G, et al. Factors influencing long-term changes in mental health after interferon-alpha treatment of chronic hepatitis C. Alimentary Pharmacology \& Therapeutics. 2009;30:1049-1059.

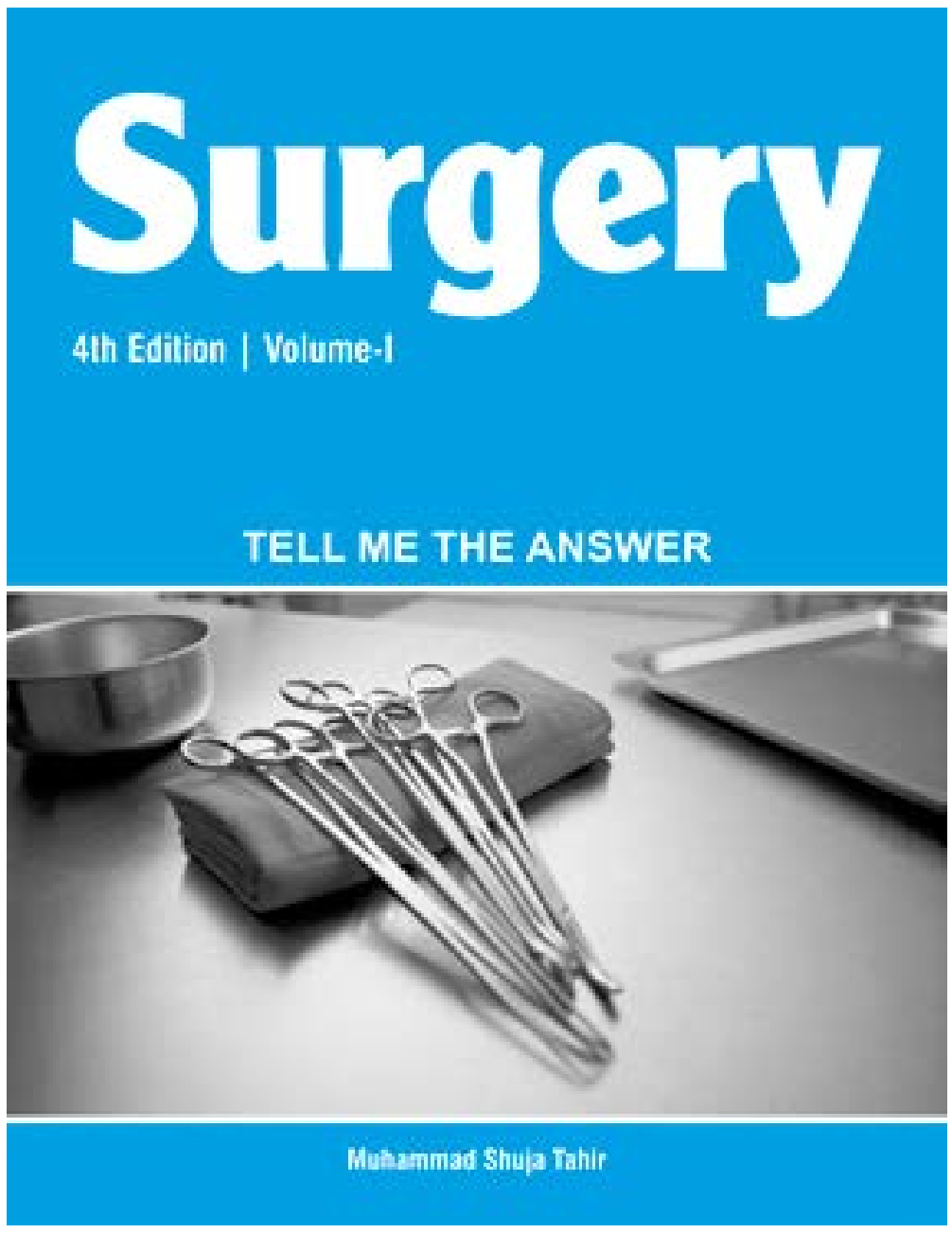

\section{AUTHORSHIP AND CONTRIBUTION DECLARATION}

\begin{tabular}{|c|l|l|l|}
\hline Sr. \# & \multicolumn{1}{|c|}{ Author-s Full Name } & \multicolumn{1}{|c|}{ Contribution to the paper } & Author=s Signature \\
\hline 1 & Dr. Mirza M. Ilyas Baig & 1st Author & \\
\hline 2 & Dr. Aftab Haider Alvi & 2nd Author & \\
\hline 3 & Dr. Nazeefa Javed & 3rd Author & \\
\hline
\end{tabular}

